\title{
Article \\ Preparation and Characterization of Glass-Fiber-Reinforced Modified Polyphenylene Oxide by a Direct Fiber Feeding Extrusion Process
}

\author{
SeungJae Ahn, Jae-Chul Lee and Ki-Young Kim *
}

Citation: Ahn, S.; Lee, J.-C.; Kim,

K.-Y. Preparation and

Characterization of Glass-Fiber-

Reinforced Modified Polyphenylene Oxide by a Direct Fiber Feeding Extrusion Process. Appl. Sci. 2021, 11, 10266. https://doi.org/10.3390/ app112110266

Academic Editor: Han-Yong Jeon

Received: 5 September 2021

Accepted: 28 October 2021

Published: 1 November 2021

Publisher's Note: MDPI stays neutral with regard to jurisdictional claims in published maps and institutional affiliations.

\author{
Material \& Component Convergence R\&D Department, Korea Institute of Industrial Technology, 143 Hanggaulro, \\ Sangnok-gu, Ansan 15588, Gyeonggi, Korea; sjahn@kitech.re.kr (S.A.); jc2@kitech.re.kr (J.-C.L.) \\ * Correspondence: kkim@kitech.re.kr; Tel.: +82-31-8040-6086
}

\begin{abstract}
Polyphenylene oxide (PPO) polymers have good mechanical, electrical, and thermal properties, but they have poor processability owing to their quite high melt viscosity. This hinders the manufacturing processes of fiber-reinforced thermoplastics that have enhanced mechanical and physical properties. Although PPO was modified by blending with polystyrene (PS) or polyamide to improve processability, the modified PPO (mPPO) still had a high melt viscosity compared with other polymers. Thus, the fiber-reinforced mPPO is manufactured by compounding with chopped fiber, while various methods are applied to manufacture the fiber-reinforced polypropylene and polyamide in order to improve properties. One of the methods is a direct fiber feeding method, which can keep the longer fiber length because of a direct and continuous roving yarn feeding without chopping. Therefore, the composite manufactured by the direct fiber feeding method is expected to improve the mechanical properties. Hence, this study aims to investigate the feasibility of a direct fiber feeding extrusion process for manufacturing glass-fiber-reinforced $\mathrm{mPPO}$ or GFmPPO. The manufactured GF/mPPO composites exhibited increased tensile and flexural properties as the fiber content increased up to $50 \mathrm{wt} \%$ of GF owing to the predominant effects of fiber content. Nevertheless, the larger core area in the cross-section micrograph of the tensile specimen of the $\mathrm{GF} / \mathrm{mPPO}$ composite with $50 \mathrm{wt} \%$ of GF was observed to reduce the fiber efficiency factor for tensile strength. Meanwhile, the impact strength of the GF/mPPO composites decreased with increasing GF content. This is attributed to the insufficient fiber length for the impact strength. As the GF content increased, the glass transition temperature slightly decreased. This result was interpreted as being a result of thermal degradation during the extrusion process to manufacture the GF/mPPO masterbatch. The results of the dynamic mechanical analyses, e.g., storage modulus and tan $\delta$, show the good correlation with the increased flexural modulus, the decreased glass transition temperature, and the impact strength as the GF content increased.
\end{abstract}

Keywords: polyphenylene oxide; glass-fiber-reinforced thermoplastic; short fiber composite; direct fiber feeding extrusion

\section{Introduction}

Glass-fiber-reinforced thermoplastics (GFRTs) are applied in various industries owing to their excellent mechanical properties, low cost, and easy processability [1]. In particular, the reprocessability and recyclability of GFRTs make them environmentally friendly [2]. Polypropylene (PP), polyamide (PA), and polybutylene terephthalate are widely used as composite matrices. Furthermore, high-performance polymer composites, such as polyphenylene oxide (PPO), polyphenylene sulfide, and polyetherimide, have been developed and are emerging as promising materials.

PPO is an amorphous polymer that exhibits good mechanical properties, thermal resistance, and dimensional stability. However, it has poor processability and a high melt viscosity because of its low chain mobility with a higher glass transition temperature $\left(\mathrm{T}_{\mathrm{g}}\right)$ of 
approximately $200^{\circ} \mathrm{C}$. To overcome this drawback, PPO is generally modified by blending with polystyrene (PS) or polyamide (PA) [3]. Because PS is a miscible polymer with PPO, phase separation does not occur in PS-modified PPO (PS-mPPO), and it exhibits good impact strength. In addition, PA-modified PPO (PA-mPPO) exhibits good mechanical properties, even though PA is an immiscible polymer with PPO.

Some studies have reported that other polymers or additives contribute to the modification of PPO or to the improvement of the interfacial strength between GF and PPO. In a study of GF/PPO composites, the PPO composites were prepared by melt-blending of PPO with GF-reinforced syndiotactic PS (GFRsPS). The tensile and flexural moduli increased with increasing GFRsPS content, whereas the tensile and flexural strengths decreased [4]. The thermotropic liquid crystal polymer (TLCP) used in the GF/TLCP/PS-mPPO reduced the damage of GF during processing and moderately increased the tensile strength of the composite owing to the fiber orientation affected by TLCP in the composite [5]. Trachte and Dibenedetto investigated PPO composites in which glass beads, GFs, and graphite fibers were used as reinforcements [6]. Their study reported that a silane coupling agent improved the tensile strength and fracture toughness of the PPO composites. $\mathrm{Li}$ et al. reported that maleic anhydride-grafted PPO (PPO-g-MA) was helpful in maintaining the fiber length during the melt processing, and the tensile strength of the GF/PA-mPPO composites was increased by PPO-g-MA owing to the improved interface adhesion [7].

The mechanical properties of GFRTs could be improved not only by material modification but also by improving the manufacturing methods. In particular, the fiber length is believed to be an important factor for improving the mechanical properties of discontinuousfiber-reinforced plastics [8-10]. A longer fiber length in GFRTs would be obtained by direct feeding of the GF roving strand to an injection molding machine or extruder. The direct fiber feeding method has already been investigated and commercially applied to polymers, such as PP and PA, because it significantly improves their mechanical properties. In the majority of the studies, chopped GF was compounded to prepare GF/mPPO composites. To the authors' knowledge, the study reported by Hadimani et al. was the only one that explored the direct feeding of GF roving yarns for GF/mPPO composites [11]. The effects of GF content, MA, and various processing methods on the thermal and mechanical properties of GF/mPPO composites were studied. The GF roving yarn was directly fed into a vent in the extruder to prepare long-fiber GF/mPPO pellets. However, the usefulness of the direct fiber feeding method has not been fully explained because of the difficulty in investigating the effects of various parameters.

In this study, a GF/mPPO composite was prepared through injection molding using a masterbatch with a GF content of approximately $50 \%$, which was prepared by the direct feeding extrusion of GF roving yarns. GF/mPPO with various fiber contents was prepared, and the mechanical and thermal properties of the GF/mPPO composites were investigated in terms of the fiber content and length. These results demonstrate the feasibility of the direct fiber feeding method to prepare a composite with a high fiber content to overcome the drawback of a highly viscous thermoplastic matrix.

\section{Experiments}

\subsection{Materials}

The mPPO used in the present study was PS-mPPO (Noryl 7310, Sabic Co., Riyadh, Saudi Arabia), which had a melt flow rate of $11 \mathrm{~g} / 10 \mathrm{~min}$ at $280^{\circ} \mathrm{C}$ under a $5.0 \mathrm{kgf}$ load. The GF roving yarns (EDR240-T835, Taishan Fiberglass Inc., Dezhou, China) were E-glass fibers. The GF had a diameter of $17 \mu \mathrm{m}$, and the linear density of the GF roving yarn was 2400 tex. According to the manufacturer, the GF roving yarn was sized for the PA matrix. The $\mathrm{mPPO}$ and $\mathrm{GF} / \mathrm{mPPO}$ masterbatches were dried at $105^{\circ} \mathrm{C}$ for $4 \mathrm{~h}$ before the extrusion process. 


\subsection{Preparation of the GF/mPPO Masterbatch}

The GF/mPPO masterbatch was prepared using an in-house lab-scale extrusion system for long-fiber thermoplastics, the scheme of which is shown in Figure 1. Both the first and second extruders were twin-screw extruders, and the L/D ratios (length to diameter) of the first and second screws were 24 and 18, respectively. More information about the extruder system has been reported in [12]. The MPPO was fed into the hopper of the first extruder, and the molten polymers were fed into the second extruder simultaneously with the GF roving yarn. The aim of the first extruder was to minimize damage to the GF roving yarn in the second extrusion process through the feeding of the molten polymer. The barrel temperature was set from $275{ }^{\circ} \mathrm{C}$ to $300{ }^{\circ} \mathrm{C}$ in the first extruder and from $300{ }^{\circ} \mathrm{C}$ to $310{ }^{\circ} \mathrm{C}$ in the second extruder. The screw RPM was 150 in the first extruder and 60 in the second extruder. The length of the GF/mPPO masterbatch was $12 \mathrm{~mm}$.

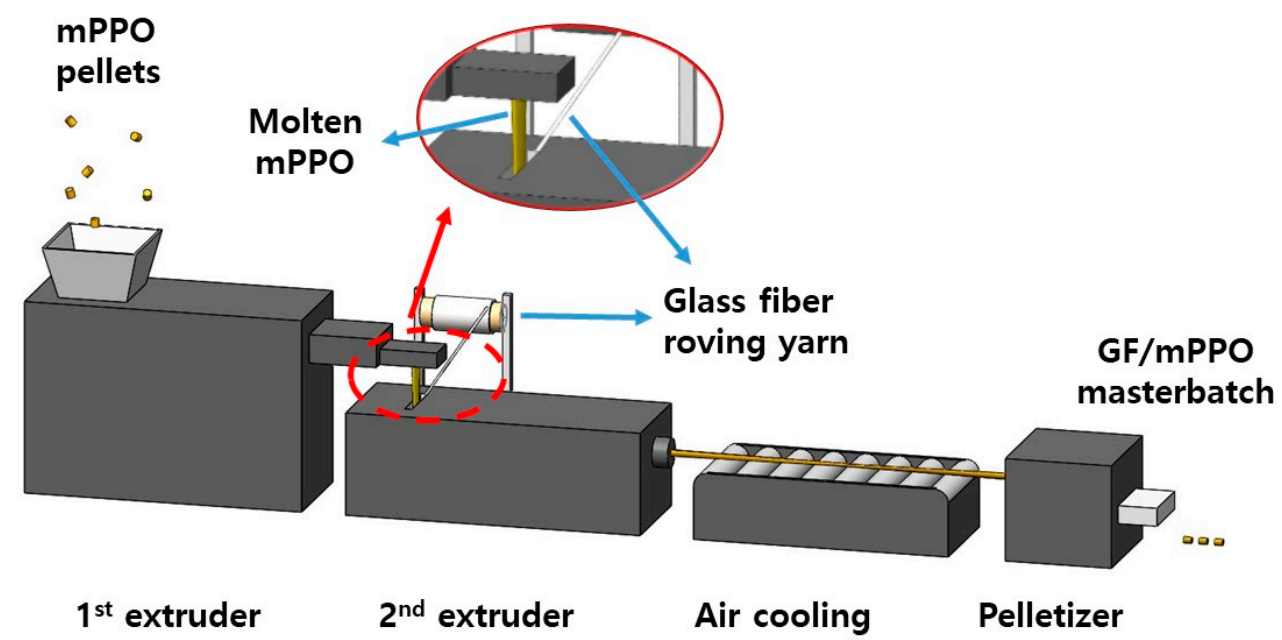

Figure 1. Scheme of extruder system to prepare the GF/mPPO masterbatch.

\subsection{Preparation of the GF/mPPO Composite}

The GF/mPPO composite was prepared using a single-screw injection molding machine. The GF/mPPO masterbatch was diluted with neat mPPO pellets to obtain the designated fiber content. The temperature of the cylinder in the injection molding machine was set from 280 to $300{ }^{\circ} \mathrm{C}$, and the molding temperature was set to $70^{\circ} \mathrm{C}$ to manufacture tensile and flexural specimens and impact test specimens.

\subsection{Characterization of the GF/mPPO Composites}

The constituent contents of the GF/mPPO masterbatch and composites were tested according to ASTM D3171. The specimen above $1 \mathrm{~g}$ was burned in a muffle furnace at $600{ }^{\circ} \mathrm{C}$ for $6 \mathrm{~h}$ under a nitrogen atmosphere. The weights of the residual fibers were measured, and the void and fiber volume fractions were calculated. For the measurement of the fiber length, some residual fibers after pyrolysis were collected, diluted with distilled water, and dispersed in a Petri dish. The lengths of the dried residual fibers were measured directly using an optical microscope. The average fiber length was determined by averaging at least 1000 fibers obtained from the specimens. The mechanical properties of the injectionmolded $\mathrm{mPPO}$ and $\mathrm{GF} / \mathrm{mPPO}$ composite specimens were evaluated according to an ASTM D638 (tensile test), ASTM D790 (flexural test), and ASTM D256 (Izod impact strength test). Tensile tests were carried out using an MTS 370 (MTS Systems Co., Cary, NC, USA) at a crosshead speed of $5 \mathrm{~mm} / \mathrm{min}$. Flexural tests were performed using an MTS 858 (MTS Systems Co., Cary, NC, USA) with a crosshead speed of $1.5 \mathrm{~mm} / \mathrm{min}$ and a span length of $57 \mathrm{~mm}$. Izod impact strength tests were performed using an IT 503 (Tinius Olsen Co. Ltd., Salfords, UK). Thermal properties were investigated using a thermogravimetric analysis (TGA) and differential scanning calorimetry (DSC). The TGA was carried out under a nitrogen atmosphere from room temperature to $800{ }^{\circ} \mathrm{C}$ using a Q500 (TA Instruments Co., 
New Castle, DE, USA) at a heating rate of $10^{\circ} \mathrm{C} / \mathrm{min}$. The DSC was carried out under a nitrogen flow from 40 to $30{ }^{\circ} \mathrm{C}$ using a Q100 (TA Instruments Co., New Castle, DE, USA) with a heating and cooling rate of $10^{\circ} \mathrm{C} / \mathrm{min}$. The dynamic mechanical analysis (DMA) was carried out using a DMA 850 (TA Instruments Co., New Castle, DE, USA) in a dual cantilever mode. The specimens were tested at a frequency of $1 \mathrm{~Hz}$ and a strain of $0.1 \%$ in a temperature range from 25 to $200^{\circ} \mathrm{C}$ and at a heating rate of $2{ }^{\circ} \mathrm{C} / \mathrm{min}$. The fracture surfaces of the specimens after the tensile test were observed with scanning electron microscopy (SEM). The specimens were coated with gold at $15 \mathrm{~mA}$, and then SEM (SU-8010, Hitachi Ltd., Tokyo, Japan) was employed to obtain SEM micrographs. The fiber orientation and distribution in the tensile specimens after polishing were observed with an LEXT OLS4000 (Olympus Co. Ltd., Tokyo, Japan) using the optical microscope mode.

\section{Results and Discussion}

\subsection{Physical Properties}

The physical properties of the masterbatch and GF/mPPO composites are listed in Table 1. The constituent contents were calculated using the flowing equations:

$$
\begin{gathered}
W_{f}=\frac{m_{f}}{m_{i}} \times 100 \\
V_{f}=\frac{m_{f}}{m_{i}} \times \frac{\rho_{c}}{\rho_{f}} 100 \\
V_{m}=\frac{m_{i}-m_{f}}{m_{i}} \times \frac{\rho_{c}}{\rho_{m}} 100 \\
V_{v}=100-\left(V_{f}+V_{m}\right)
\end{gathered}
$$

where $W_{f}$ is the fiber weight fraction, $V_{f}$ is the fiber volume fraction, and $V_{m}$ is the matrix volume fraction of the specimen; $m_{i}$ and $m_{f}$ are the mass of the initial specimen and residual fiber, respectively; $\rho_{c}, \rho_{\mathrm{f}}$, and $\rho_{\mathrm{m}}$ are the density of the specimen, fiber, and matrix, respectively.

Table 1. The physical properties of the GF/mPPO masterbatch and composites.

\begin{tabular}{ccccc}
\hline & $\begin{array}{c}\text { Density } \\
\left(\mathbf{g} / \mathbf{c m}^{\mathbf{3}} \mathbf{)}\right.\end{array}$ & $\begin{array}{c}\text { Fiber Weight } \\
\text { Fraction } \\
\mathbf{( w t} \text { \%) }\end{array}$ & $\begin{array}{c}\text { Fiber Volume } \\
\text { Fraction } \\
\text { (vol\%) }\end{array}$ & $\begin{array}{c}\text { Void Volume } \\
\text { Fraction } \\
\text { (vol\%) }\end{array}$ \\
\hline Masterbatch & 1.319 & 52.0 & 26.3 & 14.6 \\
GF/mPPO 30 & 1.275 & 29.1 & 14.5 & 1.8 \\
GF/mPPO 40 & 1.361 & 37.3 & 19.9 & 1.2 \\
GF/mPPO 50 & 1.495 & 48.9 & 28.6 & 0.7 \\
\hline
\end{tabular}

The masterbatch had a GF content of $52 \mathrm{wt} \%$. The volume fractions of the fiber and void were 26.3 and $14.6 \mathrm{vol} \%$, respectively. The high void fraction in the masterbatch was caused by the die swell of molten $\mathrm{mPPO}$ [13]. Although there were concerns about the high void fraction of the masterbatch, the void fraction in the GF/mPPO composites decreased after injection molding.

The fiber length in discontinuous fiber-reinforced thermoplastics is a major factor that influences the mechanical properties. The average residual fiber length and fiber length distribution (FLD) are listed in Table 2. The average length by number $\left(L_{n}\right)$ and average length by weight $\left(L_{w}\right)$ were calculated using the following equations:

$$
L_{n}=\frac{\sum n_{i} L_{i}}{\sum n_{i}}
$$




$$
L_{\mathrm{w}}=\frac{\sum n_{i} L_{i}^{2}}{\sum n_{i} L_{i}}
$$

Table 2. The average fiber length of the GF/mPPO masterbatch and composites.

\begin{tabular}{cccccc}
\hline & Max. $(\mu \mathrm{m})$ & Min. $(\mu \mathrm{m})$ & $\boldsymbol{L}_{\boldsymbol{n}}(\boldsymbol{\mu m})$ & $\boldsymbol{L}_{\boldsymbol{w}}(\mu \mathrm{m})$ & FLD $\left(L_{w} / L_{n}\right)$ \\
\hline Masterbatch & $10,772.80$ & 38.44 & 913.43 & 2930.57 & 3.21 \\
GF/mPPO 30 & 1187.04 & 40.17 & 298.98 & 411.52 & 1.38 \\
GF/mPPO 40 & 1153.20 & 38.56 & 294.64 & 393.99 & 1.34 \\
GF/mPPO 50 & 931.33 & 28.46 & 291.88 & 390.69 & 1.34 \\
\hline
\end{tabular}

For the composite with a GF content of $30 \mathrm{wt} \%$, the average fiber length was longer than the previously reported lengths of the short GF/mPPO composites [7,14]. Li et al. [7] reported an average fiber length of $106 \mu \mathrm{m}$ in their PPO-g-MA/PA6/GF composite, and Vaxman et al. [13] reported an average fiber length of $190 \mu \mathrm{m}$ for a short commercial $\mathrm{GF} / \mathrm{mPPO}$ composite. However, Hadimani et al. [11] reported an average fiber length of $2.28 \mathrm{~mm}$ for the direct GF roving yarn feeding to prepare the GF/mPPO composites. Although their processing is similar to the one employed in this study, the difference in the average fiber lengths would result from the different GF content of the pellets for the following injection molding. It is well known that fibers become damaged by shear stress and fiber-fiber interactions during extrusion and injection molding processes [15]. The higher fiber content leads to more fiber-fiber interaction; thus, the fibers become broken and shortened. The relatively long fibers of the GF/mPPO masterbatch degraded to shorter fibers in the composites because of fiber breakages during injection molding. The damaged and shortened fibers account for the decrease in $L_{w}$ and FLD in Table 2, which is less compared to the masterbatch and with increasing fiber length.

The fiber orientation distribution also influences the mechanical properties of discontinuousfiber-reinforced thermoplastics [16]. The fibers in the injection-molded composites are oriented along the flow direction. Figure 2 shows the cross-section images of the tensile specimens of the GF/mPPO composites. The GFs in the GF/mPPO 30 were oriented along the specimen length direction. The core region (red dash ellipse in Figure 2), where the GFs were oriented perpendicularly to the specimen length direction, can be observed in the GF/mPPO 40. Moreover, the area of the core region in the GF/mPPO 50 was increased. The core region in the injectionmolded fiber composites is mainly dependent on the fiber length, but the core region is also observed when the fiber content in the composite is high [17].

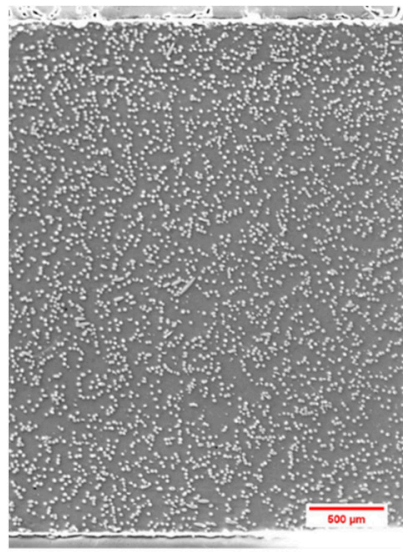

(a)

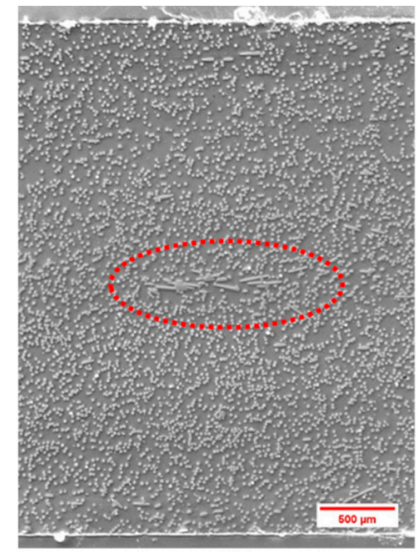

(b)

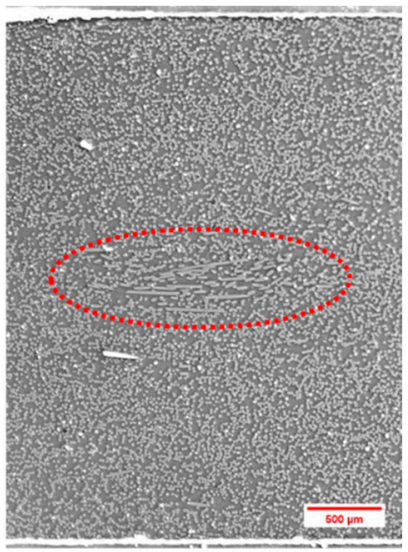

(c)

Figure 2. The cross-section images of GF/mPPO composites (the scale bar is $500 \mu \mathrm{m}$ ); (a) GF/mPPO 30, (b) GF/mPPO 40, and (c) GF/mPPO 50. 


\subsection{Mechanical Properties}

The results of the mechanical properties of the GF/mPPO composites show a dependence on the GF content, as presented in Figures 3-5. The GF/mPPO composites exhibit enhanced tensile and flexural properties compared to those of the neat mPPO. The tensile strength and modulus increased with increasing GF content. The tensile strength and tensile modulus of the $50 \mathrm{wt} \%$ GF composites increased by $186 \%$ and $500 \%$, respectively. Moreover, the flexural strength and flexural modulus increased by $130 \%$ and $452 \%$, respectively. However, the GF negatively influenced the impact strength, and the impact strength decreased by $58 \%$ for the $50 \mathrm{wt} \%$ GF composites.

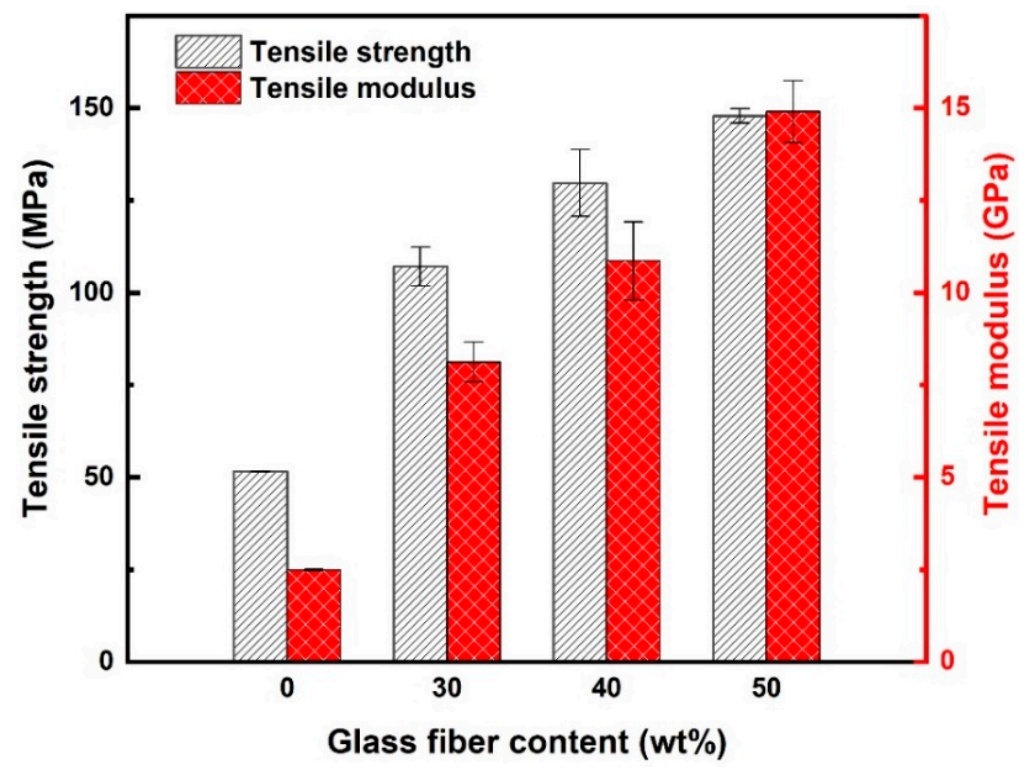

Figure 3. Effect of GF content on tensile strength and modulus of GF/mPPO composites.

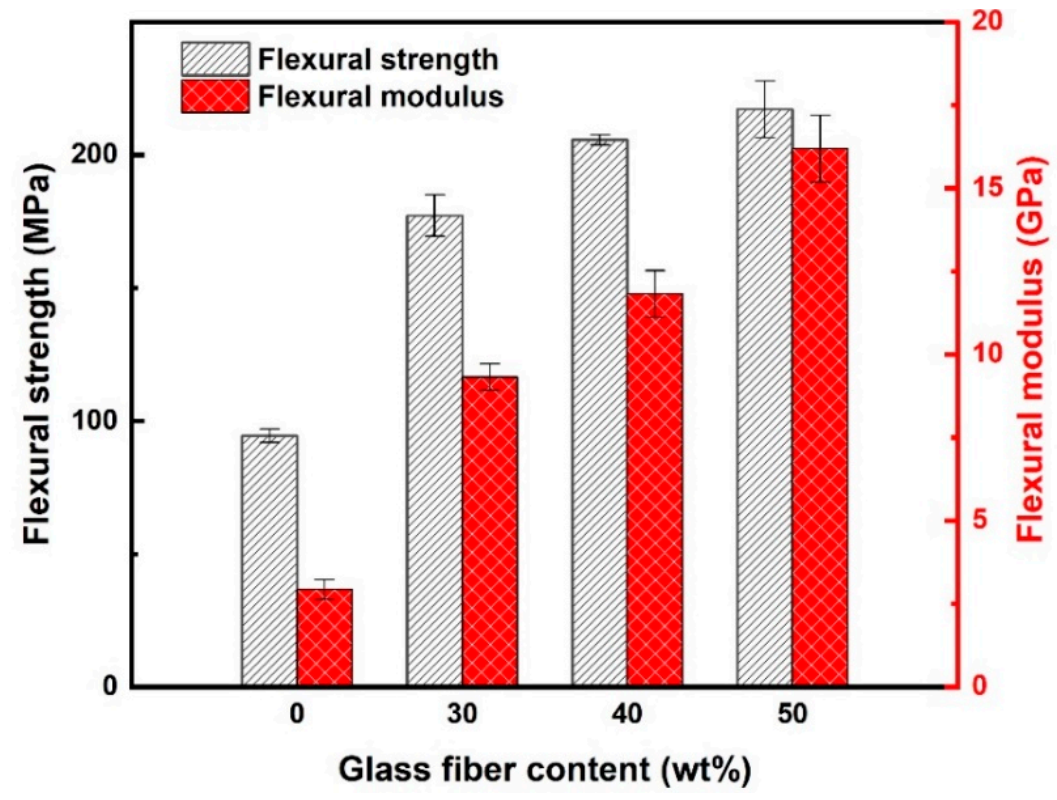

Figure 4. Effect of GF content on flexural strength and modulus of GF/mPPO composites. 


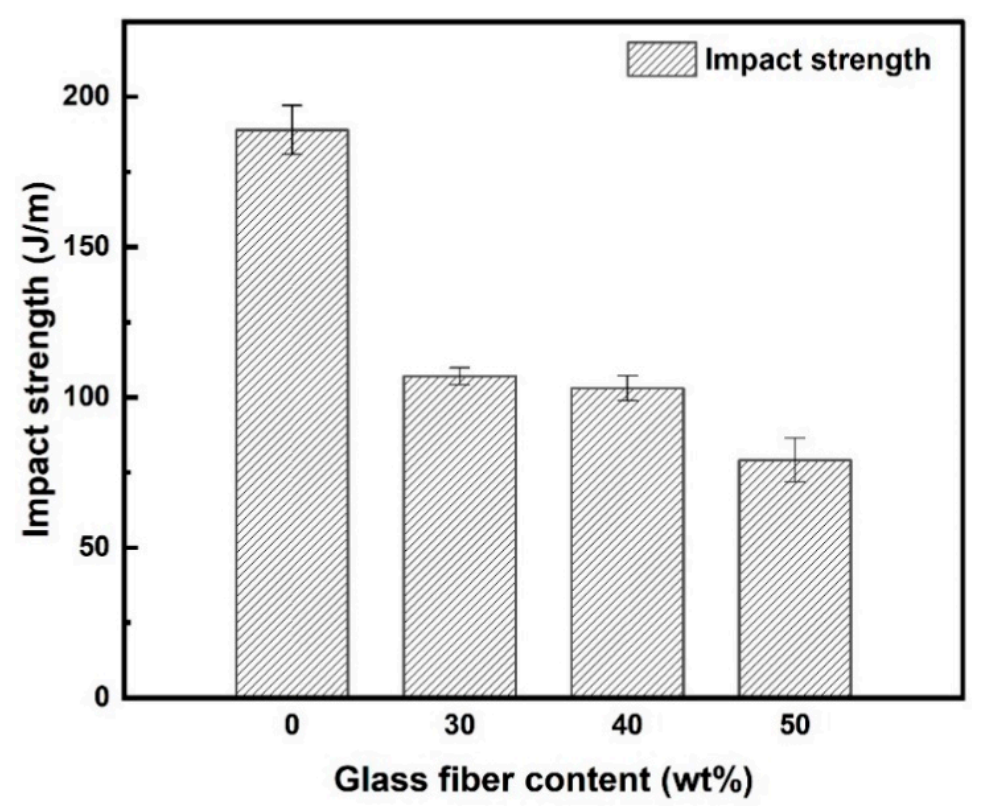

Figure 5. Effect of GF content on impact strength of GF/mPPO composites.

The advantage of the direct fiber feeding method is more pronounced in the manufacturing of composites with higher GF content than in that of composites with lower GF content with a comparison to the chopped GF composites prepared by compression molding and injection molding after the compounding process. The GF/PPO composite prepared by compression molding with a $20 \mathrm{vol} \%$ of the chopped GF has approximately $100 \mathrm{MPa}$ of the tensile strength [3]. The tensile strength of the PPO-g-MA/PA6/GF composite prepared by injection molding with $30 \mathrm{wt} \%$ of GF content is $97.1 \mathrm{MPa}$ [6]. The tensile strength of the PPO/high-impact polystyrene (HIPS)/GF composite with $30 \mathrm{wt} \%$ of GF content, prepared by injection molding, exhibits $132 \mathrm{MPa}$ [7]. The tensile strengths decrease in the GF/PPO composite and in the PPO/HIPS/GF composite when the fiber content further increases above $20 \mathrm{vol} \%$ and $23.1 \mathrm{wt} \%$ in the respective studies, whereas, in this study, the tensile strength continuously increased up to $147.9 \mathrm{MPa}$ as the fiber content increased up to $50 \mathrm{wt} \%$ of GF in the composite. This phenomenon may be explained by the decreased void fraction and the increased number of GFs oriented to the tensile direction. Therefore, it is demonstrated that the direct fiber feeding method may be more effective than the other methods for better tensile properties of the composites with a high GF content.

For discontinuous short-fiber-reinforced composites, the reinforcing effects of the GF content can be estimated using the fiber efficiency factor, which can be expressed by the modified rule of mixtures equation $[16,18]$. The fiber efficiency factors for the tensile strength and modulus were calculated using the following equations:

$$
\begin{aligned}
& \lambda_{\sigma}=\frac{\sigma_{\mathcal{c}}-\sigma_{m}\left(1-V_{f}\right)}{\sigma_{f} V_{f}} \\
& \lambda_{E}=\frac{E_{\mathcal{c}}-E_{m}\left(1-V_{f}\right)}{E_{f} V_{f}}
\end{aligned}
$$

where $\lambda_{\sigma}$ is the fiber efficiency factor for the tensile strength of the composite; $\sigma_{c}, \sigma_{m}$, and $\sigma_{f}$ are the tensile strengths of the composites, matrices, and fibers, respectively; $\lambda_{E}$ is the fiber efficiency factor of the tensile modulus of the composite; and $E_{\mathcal{C}}, E_{m}$, and $E_{f}$ are the tensile moduli of the composites, matrices, and fibers, respectively. The calculation results are listed in Table 3. Although the GF/mPPO 50 exhibited the maximum tensile strength, its $\lambda_{\sigma}$ decreased. This result is attributed to the fiber orientation distribution in the GF/mPPO 
composites. Figure 6 shows the fracture morphology of the GF/mPPO composites after the tensile test, indicating the matrix fracture, GF pullout and fracture, and debonding between the GF and the mPPO. At $50 \mathrm{wt} \%$ of GF in the GF/mPPO composite, as shown in Figure 2, the increased core area results in decreased $\lambda_{\sigma}$, although the tensile strength was enhanced. In contrast, $\lambda_{E}$ increases with increasing GF content, and $\lambda_{E}$ is higher than $\lambda_{\sigma}$. This result implies that the tensile modulus was more affected by the fiber content than by the fiber length and orientation.

Table 3. The fiber efficiency factor for tensile strength and modulus of GF/mPPO composites.

\begin{tabular}{cccc}
\hline & GF/mPPO 30 & GF/mPPO 40 & GF/mPPO 50 \\
\hline$\lambda_{\sigma}$ & 0.126 & 0.129 & 0.113 \\
$\lambda_{E}$ & 0.544 & 0.587 & 0.604 \\
\hline
\end{tabular}
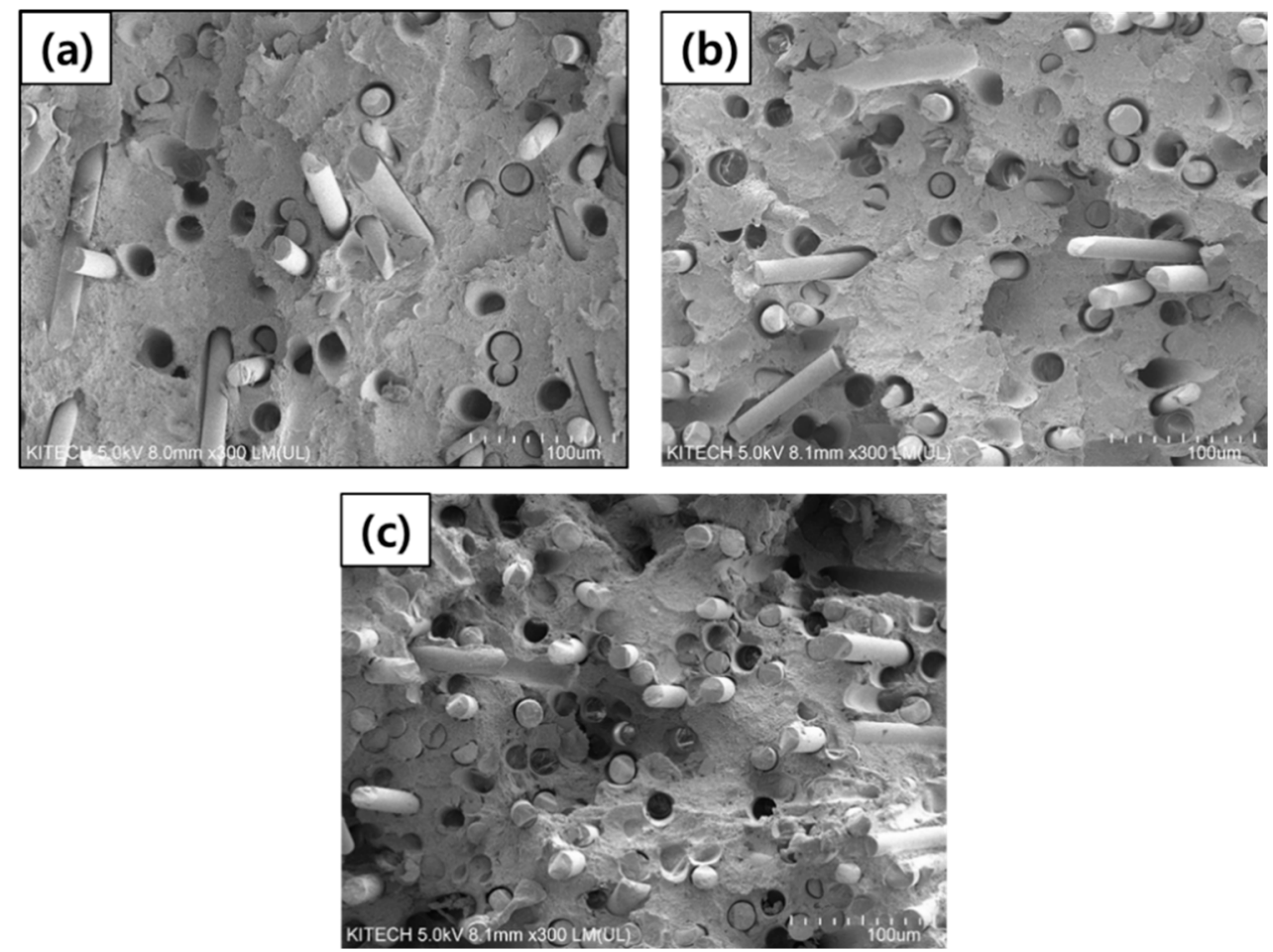

Figure 6. Fracture morphologies of the GF/mPPO composites; (a) GF/mPPO 30, (b) GF/mPPO 40, and (c) GF/mPPO 50.

In general, inorganic reinforcements, such as GF, result in the brittleness of ductile polymers [3]. Several factors can be responsible for the impact brittleness of composite laminates: (i) high localization of plastic strain in the matrix confined by surrounding fibers, (ii) stress concentration, and (iii) insufficient fiber/matrix adhesion. These complex factors can explain the decreased impact strength for higher fiber content composites along with insufficient fiber length.

\subsection{Thermal Properties}

The DSC second heating curves of the neat $\mathrm{mPPO}$ and the GF/mPPO composites are shown in Figure 7, and the glass transition temperatures $\left(\mathrm{T}_{\mathrm{g}}\right)$ are listed in Table 4 . The curves show no melting peaks, indicating that $\mathrm{mPPO}$ is an amorphous polymer. In addition, a single transition region explains the miscibility between the PS and PPO. The small endothermic peak near $120^{\circ} \mathrm{C}$ may be the LDPE added by the manufacturer as a lubricant [19]. The slight decrease in the $T_{g}$ in the GF/mPPO composites could be attributed to the thermal degradation of the $\mathrm{mPPO}$ during the preparation of the GF/mPPO masterbatch. The molten polymer was exposed to air when it was fed into the second 
extruder from the first extruder (Figure 1), leading to the thermal degradation of the $\mathrm{mPPO}$ in the masterbatch. This phenomenon has been reported in the GF/PA composite manufactured by the two extruders system, similar to the one in this study [20]. The $\mathrm{T}_{\mathrm{g}}$ of the degraded polymer chain is able to move easily at a relatively low temperature due to chain scission.

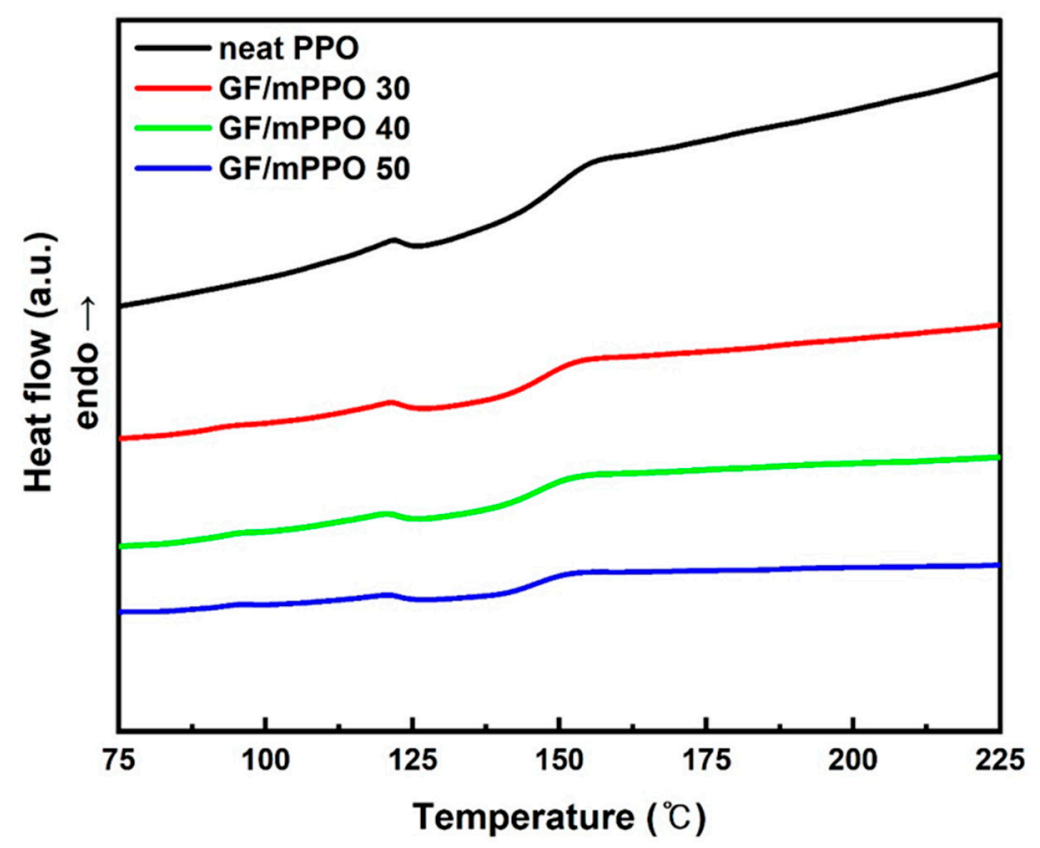

Figure 7. The 2nd heating curves of neat $\mathrm{mPPO}$ and GF/mPPO composites.

Table 4. Thermal analysis results of neat $\mathrm{mPPO}$ and GF/mPPO composites.

\begin{tabular}{cccc}
\hline & \multirow{2}{*}{$\begin{array}{c}\text { Glass Transition } \\
\text { Temperature, } \mathbf{T}_{\mathbf{g}}\left({ }^{\circ} \mathbf{C}\right)\end{array}$} & \multicolumn{2}{c}{ Decomposition Temperature } \\
\cline { 3 - 4 } & 142.45 & $\mathbf{T}_{\mathbf{5} \%}\left({ }^{\circ} \mathbf{C}\right)$ & $\mathbf{T}_{\mathbf{1 0} \%}\left({ }^{\circ} \mathbf{C}\right)$ \\
\hline Neat mPPO & 141.53 & 387.16 & 399.44 \\
GF/mPPO 30 & 140.85 & 393.81 & 405.71 \\
GF/mPPO 40 & 140.58 & 394.90 & 407.52 \\
GF/mPPO 50 & 397.21 & 410.00 \\
\hline
\end{tabular}

From the TGA analyses, the weight loss curve and the derivative thermogravimetric (DTG) curve are shown in Figure 7, and the temperatures corresponding to the weight losses of 5 (T5\%) and T (10\%) are listed in Table 4. The GF enhances the thermal stability of the matrix because it has a higher thermal stability compared to the neat matrix [21]. Although the degradation of the mPPO occurred during the preparation of the GF/mPPO masterbatch, both decomposition temperatures (T5\% and T10\%) increased with increasing GF content. This indicates that the thermal stability of the GF/mPPO composite was improved by the GF. In the DTG curve of the neat $\mathrm{mPPO}$, two peaks before and after approximately $430^{\circ} \mathrm{C}$ were superimposed (Figure 8). Because PS is less thermally stable than PPO, the peak before $430{ }^{\circ} \mathrm{C}$ corresponds to PS, and the peak after $430{ }^{\circ} \mathrm{C}$ corresponds to PPO [22]. The PS peak was reduced more than the PPO peak with increasing GF content. This indicates that the thermal degradation of PS occurred intensively during the preparation of the GF/mPPO masterbatch because of its low thermal stability. The significant thermal degradation of PS may have additional negative effects on the impact strength among the mechanical properties because high-impact PS was reduced during the manufacturing processes. 
(a)

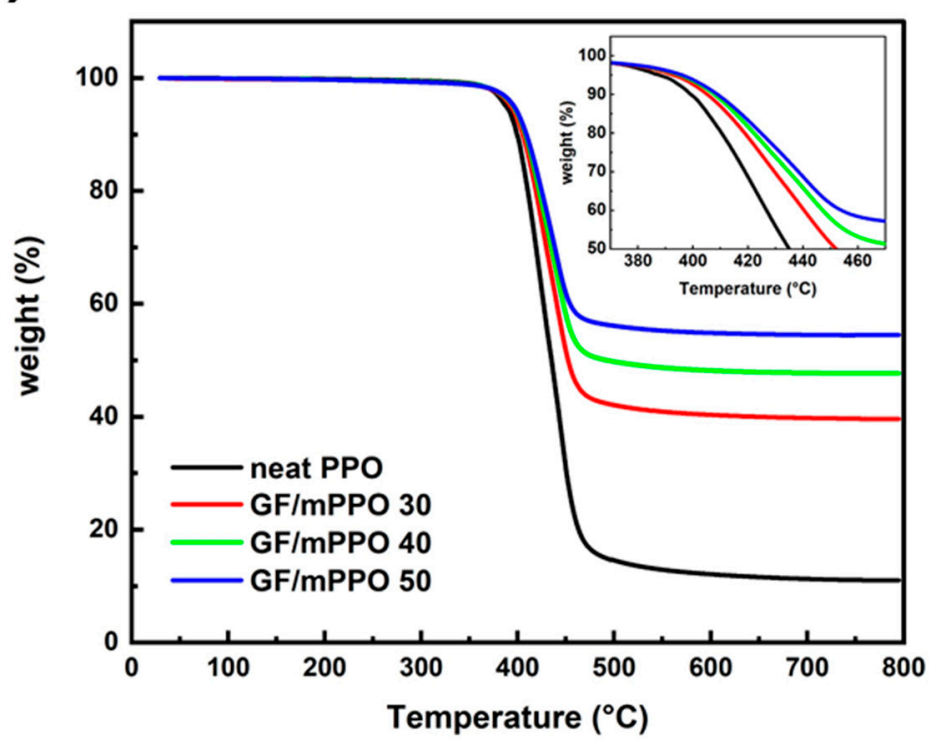

(b)

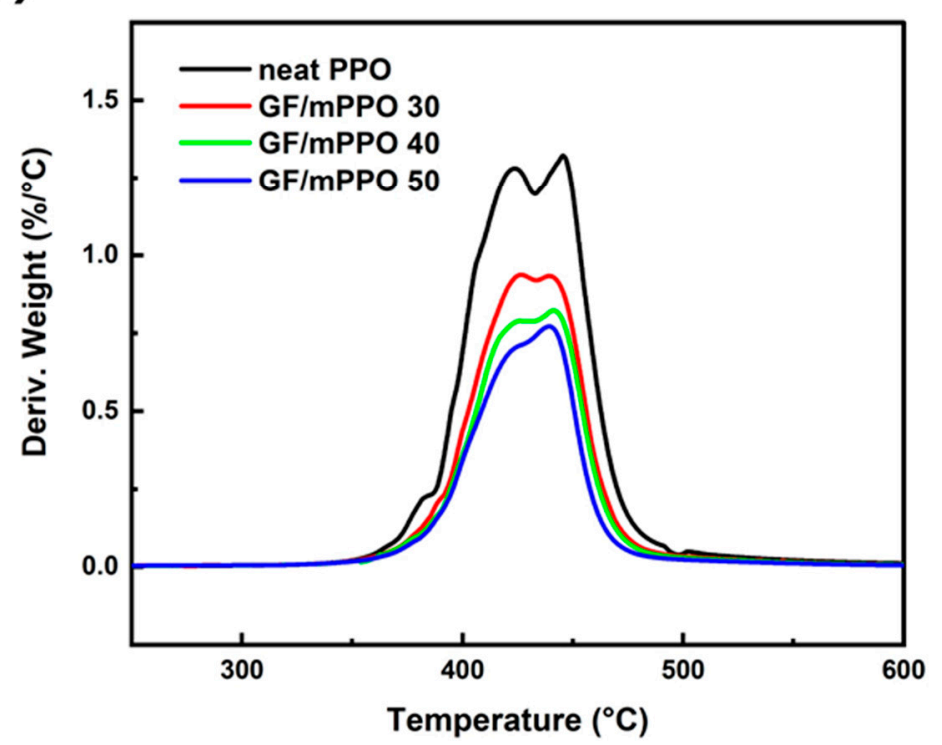

Figure 8. Typical TGA results of neat $\mathrm{mPPO}$ and GF/mPPO composites; (a) weight loss curves, and (b) derivative thermogravimetric curves.

\subsection{Dynamic Mechanical Analysis}

Figure 9 shows the dynamic mechanical properties of the neat $\mathrm{mPPO}$ and GF/mPPO composites. The storage modulus was maintained in the glassy state and can indicate the stiffness of the materials. The storage modulus was increased with increasing GF content. This trend is similar to the results of the flexural modulus in Figure 4. As the temperature increased, the storage modulus began to drop in the glass transition region where the $\mathrm{mPPO}$ transitioned from a glassy to a rubbery state. This is related to the molecular chain mobility. When the movement of the molecular chain occurs due to having enough energy, the elastic response decreases, while the viscous response increases. A high glass transition temperature means that the energy required for the movement of molecular chains is high. Generally, the $T_{g}$ increases as the fiber content and fiber length increase because the fibers hinder the movement of the molecular chains. The $T_{g}$ determined by the onset in the storage modulus was shifted to higher temperatures at the GF/mPPO 
30 compared with the neat $\mathrm{mPPO}$. However, it was found that the $\mathrm{T}_{\mathrm{g}}$ was shifted to the lower temperatures with increasing GF content, which is consistent with the DSC results (Table 5). As mentioned in the thermal analyses, a chain scission results from thermal degradation. Short molecular chains are less entangled, and this would lead to the easy movement of molecular chains. The lower $\mathrm{T}_{\mathrm{g}}$ indicates that the lower energy is needed for the molecular chain flexibility.

(a)

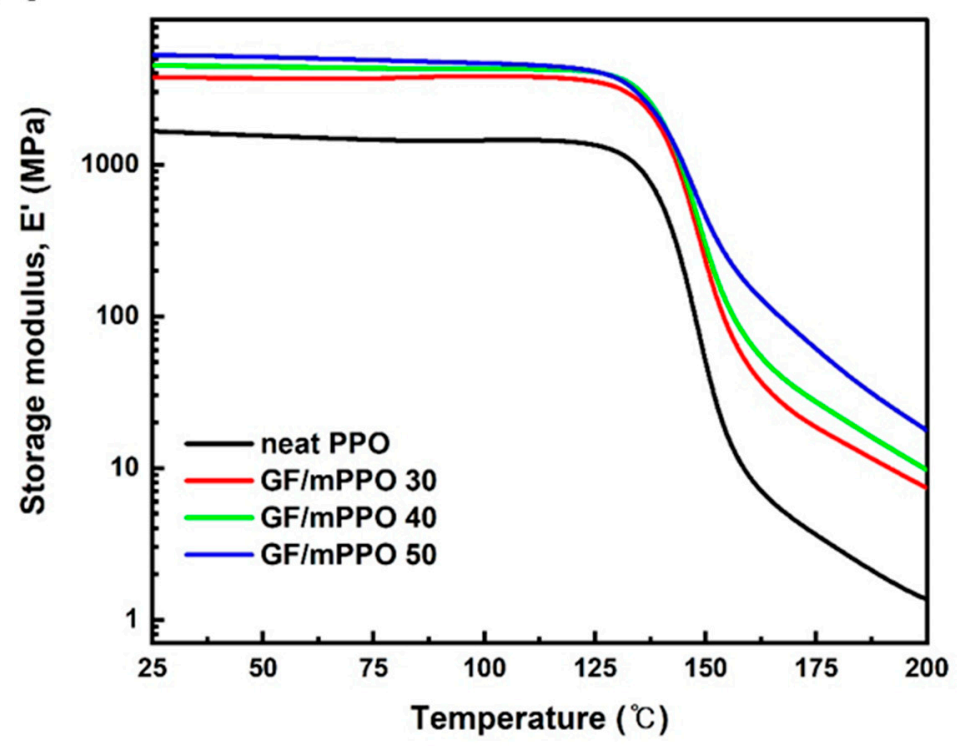

(b)

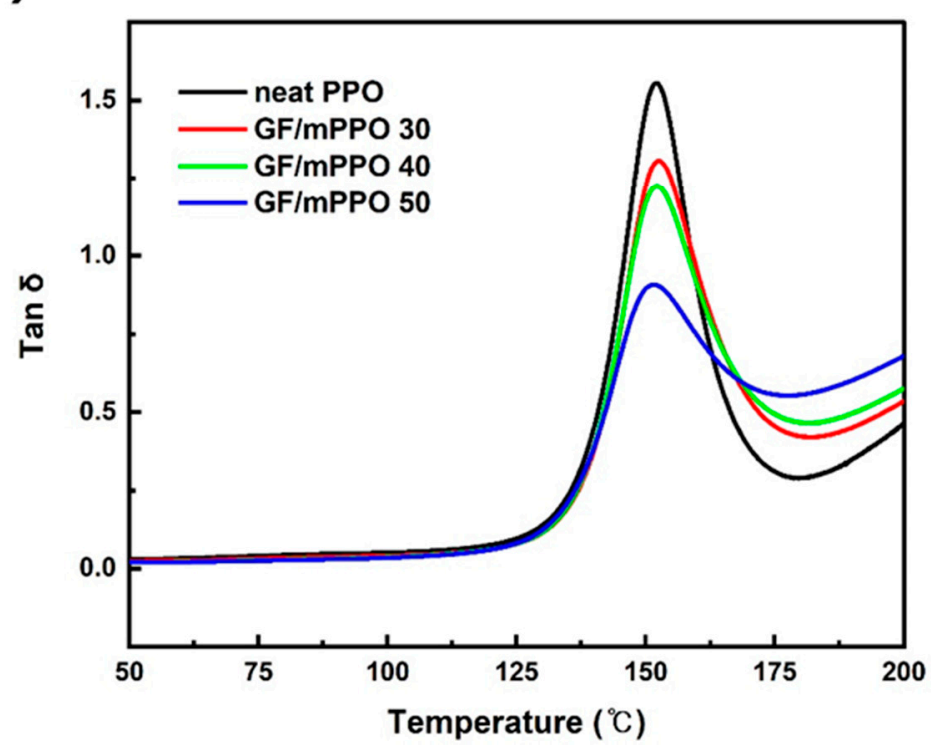

Figure 9. DMA results of the neat $\mathrm{mPPO}$ and GF/mPPO composites; (a) storage modulus, and (b) $\tan \delta$.

The value of $\tan \delta$ is the ratio between the loss modulus and storage modulus. The temperature at the $\tan \delta$ peak in the glass transition region is known as the $T_{g}$. The height of the $\tan \delta$ peak can be associated with the impact toughness. The height of the $\tan \delta$ peaks diminished with increasing GF content in the GF/mPPO composites. The lower $\tan \delta$ peak indicates less energy dissipation in the DMA tests due to the fiber-reinforcing effects by stress transfer between the fiber and matrix. Because the interfacial adhesion can 
be assumed as the same for the composites in this study, the decreased height of the $\tan \delta$ peak would be attributed to the GF content, rather than the interfacial adhesion, leading to less energy dissipation of the GF-reinforcing effects. This may be correlated with the lower impact strength for the composites with higher CF contents. Similar results are found in other studies $[23,24]$.

Table 5. Glass transition temperature determined by DMA.

\begin{tabular}{ccc}
\hline & $\begin{array}{r}\text { Onset Temperature in Storage } \\
\text { Modulus }\left({ }^{\circ} \mathbf{C}\right)\end{array}$ & $\begin{array}{c}\text { Peak Temperature in tan } \delta \\
\left({ }^{\circ} \mathbf{C}\right)\end{array}$ \\
\hline Neat mPPO & 137.81 & 152.07 \\
GF/mPPO 30 & 138.15 & 152.55 \\
GF/mPPO 40 & 137.89 & 152.18 \\
GF/mPPO 50 & 137.70 & 151.56 \\
\hline
\end{tabular}

\section{Conclusions}

In this study, the GF/mPPO composites were prepared through direct GF roving yarn-feeding extrusion. The mechanical, thermal, and thermo-mechanical properties were characterized and analyzed. The GF content had a dominant effect on all the properties. The tensile and flexural properties improved owing to the decreased void fraction as the GF content increased. However, the fiber orientation distribution in the core area can explain the reduced fiber efficiency factor for the tensile strength at $50 \mathrm{wt} \%$ of GF content. The deteriorated impact strength with increasing GF content resulted from insufficient fiber length and the lower height of the $\tan \delta$. The thermal degradation of the $\mathrm{mPPO}$ in the preparation of the GF/mPPO masterbatch led to a decrease in the $\mathrm{T}_{\mathrm{g}}$ for the GF/mPPO composites. The direct fiber feeding method demonstrated the pronounced effectiveness for the composite with the high GF content rather than with the low GF content, especially for high viscosity matrices such as the GF/mPPO composites.

Author Contributions: Conceptualization, S.A.; methodology, S.A. and K.-Y.K.; validation, S.A., J.-C.L. and K.-Y.K.; formal analysis, S.A.; investigation, S.A.; resources, K.-Y.K.; data curation, J.C.L. and K.-Y.K.; writing-original draft preparation, S.A.; writing-review and editing, K.-Y.K.; visualization, S.A.; supervision, K.-Y.K.; project administration, K.-Y.K.; funding acquisition, K.-Y.K. All authors have read and agreed to the published version of the manuscript.

Funding: This research was supported by the Technology Innovation Program (Parts and Materials Technology Development) (20011408, Development of thermoplastic composite material and part molding process technology for lightweight hydrogen electric vehicle electrical parts) funded by the Ministry of Trade, Industry and Energy (MOTIE, Republic of Korea).

Institutional Review Board Statement: Not applicable.

Informed Consent Statement: Not applicable.

Data Availability Statement: Data sharing is not applicable.

Conflicts of Interest: The authors declare no conflict of interest.

\section{References}

1. Fu, S.-F.; Lauke, B.; Mai, Y.-W. Science and Engineering of Short Fiber-Reinforced Polymer Composite, 2nd ed.; Woodhead Publishing: Oxford, UK, 2019; pp. 1-32.

2. Gopalraj, S.K.; Kärki, T. A review on the recycling of waste carbon fibre/glass fibre-reinforced composites: Fibre recovery, properties and life-cycle analysis. SN Appl. Sci. 2020, 2, 1-21.

3. Tang, W.; Guo, X.; Li, D.; Zhu, E.; Yuan, H. Simultaneous toughening of PPO/HIPS/glass fiber reinforced composites with thermoplastic rubbers. J. Appl. Polym. Sci. 2014, 131, 40299. [CrossRef]

4. Hwang, S.H.; Kim, Y.S.; Cha, H.C.; Jung, J.C. Thermal and physical properties of poly (phenylene oxide) blends with glass fiber reinforced syndiotactic polystyrene. Polymer 1999, 40, 5957-5960. [CrossRef]

5. Liu, H.; Liao, K. Tensile behavior and morphology studies of glass-fiber-reinforced polymeric in situ hybrid composites. J. Appl. Polym. Sci. 2004, 94, 211-221. [CrossRef] 
6. Trachte, K.L.; DiBenedetto, A.T. Fracture properties of polyphenylene oxide composites. Int. J. Polym. Mater. 1971, 1, 75-94. [CrossRef]

7. Li, B.; Zhang, Y.; Bai, X.; Wang, S.; Ji, J. Effect of PPO-g-MA on structures and properties of PPO/PA6/short glass fiber composites. J. Polym. Sci. Part B Polym. Phys. 2009, 47, 2188-2197. [CrossRef]

8. Ning, H.; Lu, N.; Hassen, A.A.; Chawla, K.; Selim, M.; Pillay, S. A review of Long fibre thermoplastic (LFT) composites. Int. Mater. Rev. 2020, 65, 164-188. [CrossRef]

9. Yan, X.; Cao, S. Structure and interfacial shear strength of polypropylene-glass fiber/carbon fiber hybrid composites fabricated by direct fiber feeding injection molding. Compos. Struct. 2018, 185, 362-372. [CrossRef]

10. Truckenmuller, F.M. Direct processing of continuous fibers onto injection molding machines. J. Reinf. Plasti. Compos. 1993, 12, 624-632. [CrossRef]

11. Hadimani, P.; Narasimha Murthy, H.N.; Mudbidre, R. Thermal and mechanical properties of glass fibre reinforced polyphenylene ether/polystyrene/nylon-6 ternary blends. Polym. Polym. Compos. 2021, 29, 1075-1088.

12. An, H.J.; Kim, J.S.; Kim, K.Y.; Lim, D.Y.; Kim, D.H. Mechanical and thermal properties of long carbon fiber-reinforced polyamide 6 composites. Fibers Polym. 2014, 15, 2355-2359. [CrossRef]

13. Vaxman, A.; Narkis, M.; Siegmann, A.; Kenig, S. Void formation in short-fiber thermoplastic composites. Polym. Compos. 1989, 10, 449-453. [CrossRef]

14. Vaxman, A.; Narkis, M.; Siegmann, A.; Kenig, S. Short fiber reinforced thermoplastics. II. Interrelation between fiber orientation and rheological properties of glass fiber-reinforced Noryl. Polym. Compos. 1989, 10, 84-91. [CrossRef]

15. Vaxman, A.; Narkis, M.; Siegmann, A.; Kenig, S. Short-Fiber Thermoplastics Composites: Fiber Fracture During Melt Processing; Wiley Encyclopedia of Composites: Hoboken, NJ, USA, 2011; pp. 1-19.

16. Fu, S.Y.; Hu, X.; Yue, C.Y. Effects of fiber length and orientation distributions on the mechanical properties of short-fiber-reinforced polymers a review. J. Soc. Mater. Sci. 1999, 48, 74-83. [CrossRef]

17. Tseng, H.C.; Chang, R.Y.; Hsu, C.H. Numerical prediction of fiber orientation and mechanical performance for short/long glass and carbon fiber-reinforced composites. Compos. Sci. Technol. 2017, 144, 51-56. [CrossRef]

18. Fu, S.Y.; Lauke, B.; Mäder, E.; Yue, C.Y.; Hu, X. Tensile properties of short-glass-fiber-and short-carbon-fiber-reinforced polypropylene composites. Compos. Part A Appl. Sci. Manuf. 2000, 31, 1117-1125. [CrossRef]

19. Bair, H.E. Quantitative thermal analysis of polyblends. Polym. Eng. Sci. 1970, 10, 247-250. [CrossRef]

20. Whitfield, T.; Kuboki, T.; Wood, J.; Ugresic, V.; Sathyanarayana, S.; Dagnon, K. Thermal properties of glass fiber reinforced polyamide 6 composites throughout the direct long-fiber reinforced thermoplastic process. Polym. Eng. Sci. 2018, 58, 46-54. [CrossRef]

21. Ota, W.N.; Amico, S.C.; Satyanarayana, K.G. Studies on the combined effect of injection temperature and fiber content on the properties of polypropylene-glass fiber composites. Compos. Sci. Technol. 2005, 65, 873-881. [CrossRef]

22. Jachowicz, J.; Kryszewski, M.; Mucha, M. Thermal degradation of the blend poly (2,6-dimethyl-1,4-phenylene oxide)-polystyrene. Macromolecules 1984, 17, 1315-1321. [CrossRef]

23. Sherif, G.; Chukov, D.I.; Tcherdyntsev, V.V.; Torokhov, V.G.; Zherebtsov, D.D. Effect of Glass Fibers Thermal Treatment on the Mechanical and Thermal Behavior of Polysulfone Based Composites. Polymers 2020, 12, 902. [CrossRef] [PubMed]

24. Chukov, D.I.; Nematulloev, S.G.; Tcherdyntsev, V.V.; Torokhov, V.G.; Stepashkin, A.A.; Zadorozhnyy, M.Y.; Zherebtsov, D.D.; Sherif, G. Structure and Properties of Polysulfone Filled with Modified Twill Weave Carbon Fabrics. Polymers 2020, 12, 50. [CrossRef] [PubMed] 